\title{
Ischemic preconditioning or heat shock pretreatment ameliorates neuronal apoptosis following hypothermic circulatory arrest
}

\author{
Chi-Hsiao Yeh, MD \\ Yao-Chang Wang, MD \\ Yi-Cheng Wu, MD \\ Yu-Min Lin \\ Pyng Jing Lin, MD
}

From the Division of Thoracic and Cardio-
vascular Surgery, Chang Gung Memorial
Hospital, Keelung, Taiwan.

This research was supported by grant CMRP-1200 from the Chang Gung Memorial Hospital, Taipei, Taiwan.

Received for publication July 9, 2003; revisions requested Nov 26, 2003; accepted for publication Dec 11, 2003.

Address for reprints: Chi-Hsiao Yeh, MD, Division of Thoracic and Cardiovascular Surgery, Chang Gung Memorial Hospital, 222 Mai-Chin Road, Keelung, Taiwan 204 (E-mail: yehccl@cgmh.org.tw).

J Thorac Cardiovasc Surg 2004;128:203-10 $0022-5223 / \$ 30.00$

Copyright @ 2003 by The American Association for Thoracic Surgery

doi:10.1016/j.jtcvs.2003.12.010
Objective: Hypothermic circulatory arrest has been widely used in complex cardiac and aortic surgery. Stroke and/or neurologic injury can occur after prolonged hypothermic circulatory arrest, possibly due to apoptosis. Ischemic preconditioning has been widely used as a neuroprotective tool, but its application in neuronal injury under hypothermic circulatory arrest has never been studied.

Methods: Forty male New Zealand white rabbits were placed on closed-chest cardiopulmonary bypass, subjected to hypothermic circulatory arrest, and rewarmed to normothermia. Experimental groups were treated with heat shock or ischemic preconditioning before hypothermic circulatory arrest. Hippocampal CA1 neurons were analyzed histopathologically. Apoptosis was confirmed by TUNEL assay and Western blot analysis, and serum S-100 $\beta$ levels, c-Fos and Bcl- 2 antibodies, and caspase-3 and heat shock protein 70 levels were measured.

Results: After 2-hour hypothermic circulatory arrest and 4-hour reperfusion, apoptosis was observed in hippocampal CA1 neurons with elevation of serum S-100 $\beta$ levels, which could be ameliorated by ischemic preconditioning or heat shock manipulations. TUNEL-positive nuclear expression of caspase- 3 increased after hypothermic circulatory arrest $(3.08 \% \pm 0.71 \%, P<.001)$ and was diminished with ischemic preconditioning $(1.61 \% \pm 0.42 \%)$ and heat shock $(1.72 \% \pm 0.38 \%)$ manipulations. Ischemic preconditioning or heat shock manipulations produced diverse patterns of heat shock protein $70, \mathrm{c}-\mathrm{Fos}$, and Bcl-2 protein expression, suggesting that these manipulations provide neuroprotection via different pathways.

Conclusions: Ischemic preconditioning and heat shock can attenuate hippocampal CA1 neuronal apoptosis after prolonged hypothermic circulatory arrest under cardiopulmonary bypass. The expression of heat shock protein 70 may not play a major role in the first window of ischemic preconditioning-induced neuroprotection.

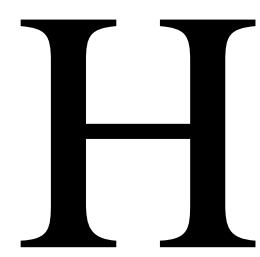
ypothermic circulatory arrest (HCA) is frequently used for cerebral protection during aortic arch surgery and in cases of complex congenital heart disease. ${ }^{1,2}$ However, the main limitation of HCA is time. At a brain temperature of $10^{\circ} \mathrm{C}$ to $15^{\circ} \mathrm{C}$, the onset of permanent neurologic injury is delayed 40 to 50 minutes. ${ }^{3}$ Selective antegrade cerebral perfusion and retrograde cerebral perfusion $^{4}$ are other protective methods used during aortic arch surgery but are associated with minor postoperative neurologic deficits. Therefore, the search continues for other methods to increase the permissible period of HCA.

HCA-induced neurologic sequelae result from neuronal cell death, including necrosis and apoptosis. The pathologic neuronal damage of HCA includes neuronal 
necrosis of the hippocampus, neocortex, basal ganglia, and cerebellum. ${ }^{5}$ Apoptosis is an additional cause of post-HCA neurologic injury ${ }^{6}$ and may explain the learning and memory deficits and impaired intellectual development seen after HCA. The implications of the selective destruction of the CA1 region are not known and require further investigation.

Animal studies have shown that global forebrain ischemia leads to a selective and delayed degeneration of hippocampal CA1 pyramidal neurons. ${ }^{7,8}$ Preconditioning, a potent endogenous protective mechanism, significantly attenuates the selective vulnerability of neurons to ischemia. ${ }^{9}$ Thus, exposure to a brief, nondamaging period of ischemia before an ischemic insult enhances the resistance of the brain to neuronal damage, a phenomenon referred to as ischemic preconditioning (IP)..$^{10,11}$

The triggering factors and effectors of IP have been under intense investigation. The elucidation of endogenous mechanisms of IP against ischemia may lead to new therapeutic strategies that enhance neuroprotection under HCA. The acquisition of ischemic tolerance by IP has been related to the induction of heat shock proteins (HSPs), ${ }^{12,13}$ which prevent the disruption of proteins and bind to abnormal proteins until they are refolded or disintegrated.

We hypothesized that IP can attenuate the neuronal apoptosis that causes neuronal injury seen after HCA and results in increased HSP production and that HSPs can attenuate neuronal apoptosis after HCA. We sought to characterize the nature of neuronal cell death after HCA to determine whether IP or HSP reduces neuronal apoptosis in a rabbit model.

\section{Materials and Methods}

\section{Hypothermic Circulatory Arrest Using Cardiopulmonary Bypass}

Forty male New Zealand white rabbits $(2.5-3.5 \mathrm{~kg})$ were premedicated with ketamine $(10 \mathrm{mg} / \mathrm{kg}$ intramuscularly), anesthetized with sodium pentobarbital $(30 \mathrm{mg} / \mathrm{kg}$ intravenously), and then given intermittent boluses of pentobarbital $(5 \mathrm{mg} / \mathrm{kg})$ and diazepam $(5 \mathrm{mg})$ as needed. Animals were intubated and ventilated with oxygen-enriched room air using a respirator. The left femoral artery and vein were catheterized for blood pressure monitoring and fluid administration, respectively. Nasopharyngeal and rectal temperatures were monitored. After systemic heparinization (250 $\mathrm{U} / \mathrm{kg}$ intravenously), the right femoral artery and vein were cannulated for closed-chest cardiopulmonary bypass (CPB), which was instituted with a membrane oxygenator (Maxima Plus oxygenation system, Medtronic, Inc, Cardiopulmonary Division, Anaheim, Calif) at a flow rate at $50 \mathrm{~mL} / \mathrm{kg} / \mathrm{min}$. Animals were surface cooled (using ice bags around the head and a cooling blanket) to a nasopharyngeal temperature of $18^{\circ} \mathrm{C}$ and $\mathrm{CPB}$ was terminated. During CPB, mean arterial pressure was maintained around 40 to $60 \mathrm{~mm} \mathrm{Hg}$. Circulatory arrest was maintained for 2 hours at $18^{\circ} \mathrm{C}$, followed by the reinstitution of $\mathrm{CPB}$ and rewarming. At normothermia $\left(37^{\circ} \mathrm{C}\right)$, animals were weaned from $\mathrm{CPB}$ and decannulated, and protamine was administered.
Rabbits were monitored for 4 hours after HCA and remained anesthetized on a ventilator. Animals were killed humanely while fully anesthetized and were perfused with warm saline solution and/or 4\% paraformaldehyde. All animals received humane care in compliance with the "Guide for the Care and Use of Laboratory Animals" (National Institutes of Health publication no. 85-23, revised in 1985).

\section{Experimental Protocol}

Rabbits were randomly divided into 4 groups $(\mathrm{n}=10)$ as follows.

Controls: body temperature during $\mathrm{CPB}$ was kept around $37^{\circ} \mathrm{C}$ and HCA was not performed.

HS: nasopharyngeal temperature was elevated to $43^{\circ} \mathrm{C}$ for 15 minutes using an external blanket before $\mathrm{CPB}$, and $\mathrm{HCA}$ was performed for 2 hours.

PC: IP ( 3 cycles of 2.5-minute ischemia followed by 5-minute reperfusion) was performed 2 hours before $\mathrm{CPB}$; ischemia was induced by clamping the 3 main branches of the aortic arch accessed from the neck incision, and 2-hour HCA was performed followed by 4-hour reperfusion.

NPC: HCA was performed for 2 hours without any other manipulation after institution of $\mathrm{CPB}$.

\section{Serum S-100ß Levels}

Concentrations of serum S-100 $\beta$ were determined in mixed venous blood samples at induction of anesthesia, after the completion of IP or heat shock, 5 minutes before HCA, 10 minutes after resuming CPB after 2-hour arrest, at rewarming to normothermia, and 4 hours after reperfusion. After centrifugation, the samples were frozen to $-20^{\circ} \mathrm{C}$ for batch analysis. Serum S- $100 \beta$ levels were measured using a luminescence immunoassay kit (Sangtec-100, LIA-mat; Sangtec Medical AB, Bromma, Sweden) and expressed as an increase-fold of S-100 $\beta$ levels above baseline values.

\section{In Vitro Apoptosis Studies}

Terminal deoxynucleotidyl transferase-mediated dUTP-biotin nick-end labeling (TUNEL) was performed as previously described. ${ }^{14}$ Paraffin sections were affixed and deparaffinized. After mounting, the sections were examined by light microscopy, and labeled nuclei were easily identified from the unstained background. To quantify apoptosis, 500 nuclei in the CA1 pyramidal cell layer were identified in 10 randomly selected $\times 400$ highpower fields per section. Apoptotic cell counts were expressed as a percentage of the total number of nuclei counted.

\section{Western Blot Analysis}

Tissue levels of intact and cleaved caspase-3 and HSP70 were determined by Western blot analysis as described previously. ${ }^{14}$ Membranes were blocked and probed with a monoclonal anticaspase-3 and anti-HSP-70 antibodies (Neomarkers, Inc, Fremont, Calif) at 1:200 dilution for 2 hours. Primary antibody binding was revealed using an anti-mouse peroxidase conjugate (Dako, Carpinteria, Calif) for 1 hour and the ECL chemiluminescent detection system (Amersham Life Science). The immunoreactive bands were quantified by digital densitometric imaging (Kodak 1D Image Analysis software; Eastman Kodak Co, Rochester, NY). 


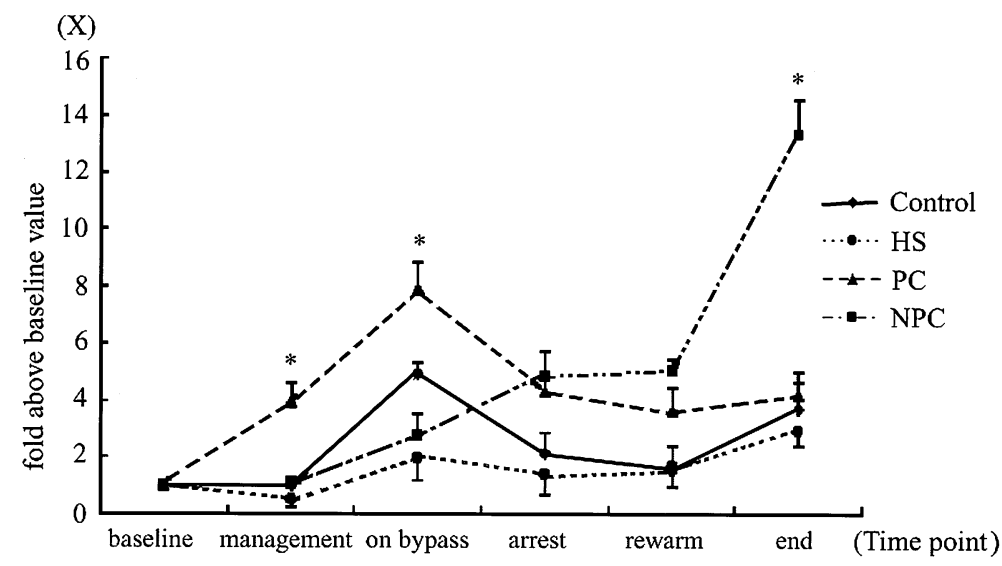

Figure 1. Changes in serum S-100 $\beta$ levels. Baseline, Induction of anesthesia; management, after the completion of IP or heat shock; on bypass, 5 minutes before HCA; arrest, 10 minutes after resuming CPB after 2-hour HCA; rewarming, rewarming to normothermia; end, 4 hours after reperfusion. Asterisk denotes a statistically significant increase $(P<.05)$ in serum $S-100 \beta$ levels from control values. Data are mean \pm SEM from 4 different experimental groups.

\section{Immunohistochemical Analysis}

The immunohistochemical procedure was performed with the parietal section including the hippocampus. The avidin-biotin peroxidase method was used for free-floating sections. Commercially available polyclonal antibodies for c-Fos (Santa Cruz Biotechnology, Inc, Santa Cruz, Calif), monoclonal antibody for Bcl-2 (Neomarkers), and monoclonal anti-caspase-3 and anti-HSP-70 antibodies (Neomarkers) were used as primary antibodies. Each section was incubated with a primary antibody overnight at $4^{\circ} \mathrm{C}$. A $0.05-\mathrm{mol} / \mathrm{L}$ Tris- $\mathrm{HCl}$ buffer solution ( $\mathrm{pH} 7.6$ ) with $0.3 \%$ Triton-X was used throughout the entire immunohistochemical procedure.

\section{Data Analysis}

Data are expressed as mean \pm standard error of the mean (SEM). Data were entered into an Excel spreadsheet (Microsoft Corporation, Redmond, Wash) and analyzed using SPSS software version 8.0 (SPSS, Inc, Chicago, Ill). Differences among groups were analyzed by 1-way analysis of variance followed by Tukey multiple comparison procedure.

\section{Results}

\section{Serum Level of S-100ß}

An average threefold increase in S- $100 \beta$ levels from baseline was observed in control ( $3.7 \pm 1.0$-fold increase), PC ( $4.2 \pm 0.8$-fold increase), and HS ( $2.9 \pm 0.5$-fold increase) groups 4 hours after the end of CPB $(P=.02)$. Serum S-100 $\beta$ concentration after 4-hour reperfusion was significantly higher in the NPC group $(13.3 \pm 1.2$-fold increase) than in other groups $(P<.001)$. After IP manipulation, serum S-100 $\beta$ levels were significantly higher in the PC group than in other groups $(P<.001)$ but decreased to control and HS group levels after 4-hour reperfusion, suggesting that IP induced sublethal neuronal injury and provided neuroprotection. Increased serum S-100 $\beta$ levels in the
HS group remained low through the experiment (Figure 1). Both HS and PC groups showed increases in serum S- $100 \beta$ levels similar to controls after 4-hour reperfusion, suggesting that both manipulations ameliorate neuronal damage to the same level produced without HCA.

\section{Assessment of Apoptotic Cell Death Following HCA}

Apoptosis was detected using the TUNEL method, which allows in situ labeling of intranucleosomal DNA breaks in cell nuclei (Figure 2). As expected, sections from control animals showed minimal apoptotic nuclei $(0.69 \% \pm$ $0.28 \%$ ), whereas TUNEL-positive cells were observed in experimental groups after HCA. HCA induced significant $(P<.001)$ neuronal apoptosis in the CA1 neuronal layers $(1.72 \% \pm 0.38 \%, 3.08 \% \pm 0.71 \%$, and $1.61 \% \pm 0.42 \%$ of apoptotic CA1 neuronal cells were identified in the HS, NPC, and PC groups, respectively). The number of DNA nick-end-labeled cells was significantly reduced in the hippocampal CA1 layer in the HS and PC groups $(P<.001)$ compared with the NPC group. IP or heat shock before HCA significantly lessened neuronal apoptosis induced by prolonged circulatory arrest.

\section{HSP70 and Caspase-3}

The induction of HSP70 and caspase- 3 in the hippocampus after HCA was determined by Western blot analysis (Figure $3, A$ and $B$ ). In the NPC group, HSP70 remained undetectable in hippocampal protein extracts after CPB. However, manipulations with heat shock before 2-hour HCA induced significantly more accumulation of HSP70 in hippocampal CA1 cells in the HS group $(2767 \pm 241 \mathrm{U}, P<.001$ vs all 3 groups). HSP70 expression observed 4 hours after HCA 


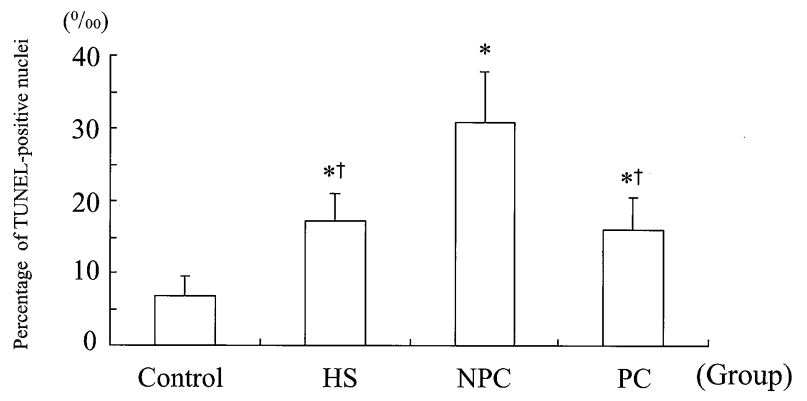

Figure 2. Effect of the HCA-induced neuronal apoptosis. Symbols denote a statistically significant increase $(P<.05)$ compared with the control $(*)$ or NPC $(t)$ group.

was significantly lower in the NPC group $(582 \pm 62 \mathrm{U})$ than in the PC $(1408 \pm 139 \mathrm{U})$ and control $(1126 \pm 141 \mathrm{U})$ groups $(P<.001)$. Immunostaining with monoclonal antibodies raised against HSP70 (Figure 4, $C$ ) and caspase-3 (Figure $4, D$ ) was performed 4 hours after the HCA insult to confirm Western blot results. Using digital densitometry, the expression of caspase- 3 protein 4 hours after HCA was significantly higher in the NPC group $(24127 \pm 5590 \mathrm{U})$ than in the control $(13936 \pm 1928 \mathrm{U}, P<.01)$, HS $(15263$ $\pm 5589 \mathrm{U}, P=.03)$, or PC groups $(12925 \pm 4296 \mathrm{U}, P<$ .01 ), a finding consistent with the TUNEL findings. Western blotting showed that IP had neuroprotective effects on inhibition of caspase-3 activation and prevented hippocampal CA1 neuronal apoptosis in a manner similar to the HS group but without inducing the same HSP70 level, suggesting that the mechanism of IP-induced hippocampal CA1 neuroprotection in HCA under CPB did not involve HSP.

\section{Bcl-2 and c-Fos Expression}

The induction of Bcl-2 and c-Fos proteins in the hippocampus was examined after HCA using immunohistochemistry (Figure 4, $A$ and $B$ ). As expected, no Bcl-2 expression was observed in hippocampal CA1 neurons (Figure 4, A) of control and NPC animals. In contrast, the IP and heat shock manipulations induced a strong Bcl-2 labeling of the CA1 neurons, comparable to that observed in hippocampal CA1 sections from control and NPC groups. c-Fos expression was strong in the control, PC, and HS groups (Figure 4, B). $\mathrm{CPB}$ induced an inflammatory response that increased the expression of c-Fos protein, which further increased with IP or heat shock manipulations and decreased with HCA.

\section{Discussion}

The current results indicate that IP and heat shock may improve cerebral outcome after prolonged HCA, confirming the previously reported neuroprotective effect of IP. ${ }^{10,11}$ Shake and colleagues ${ }^{15}$ reported the benefit of pharmacologically induced IP on neuroprotection during HCA. Brain injury during cardiac surgery under HCA has been attributed to the extreme manipulations of CPB flow rate and $\mathrm{HCA},{ }^{16}$ which exacerbate the severity of cerebral ischemiareperfusion injury associated with HCA. Although most of the early imaging changes in the brain subsided within days to weeks after surgery without major neurologic deficits, ${ }^{17}$ their consequences may be further potentiated in the presence of HCA-induced hypoxic-ischemic brain injury. Delayed cell death via apoptotic pathways is of special interest because of the potential to intercept this process. ${ }^{18}$

Increased levels of $S-100 \beta$ protein have been measured after cardiac operations, stroke, and several other neurologic disorders. This marker has been adopted for clinical use by many cardiac surgeons, with the expectation that repeated measurements could indicate brain injury postoperatively. ${ }^{19}$ In the present study, in response to ischemic brain insult, S- $100 \beta$ levels increased significantly shortly after rewarming was initiated. Smaller increases in S-100 $\beta$ concentrations occurred after reperfusion in IP-treated animals, which supports the theory that better brain protection is present after IP.

IP, a phenomenon whereby a brief episode of sublethal ischemia and other nonlethal stressors produce protection against a subsequent detrimental ischemic insult, had been described in the heart ${ }^{20}$ and in the brain. ${ }^{21}$ There are 2 forms of IP, early and late. Early preconditioning occurs within the first few hours of an ischemic insult and its mechanism is thought to be related to the $\mathrm{Na} / \mathrm{K}$ ATPase channel on the inner mitochondrial membrane. ${ }^{15}$ Late preconditioning, on the other hand, occurs usually after 4 to 6 hours up to a maximum effect at 24 hours in response to ischemia and had been related to the induction of HSPs. ${ }^{10}$ HSPs have been classified as part of a larger family of proteins designated as molecular chaperones, and in this capacity could provide support to proteins and enzymes threatened by acute ischemia. Hyperthermia pretreatment of cells in culture can induce heat tolerance, ${ }^{22}$ probably via the induction of HSPs. HSPs may act as molecular chaperones, preventing proteins from aggregating or denaturing under conditions of physiological stress. ${ }^{23}$ The expression of HSPs may be involved in a cascade of events leading to neuroprotection, depending on the severity of the insult, the liability of the different types of cells, and the availability of cochaperone proteins. ${ }^{24}$ However, induction of HSPs in hippocampal neurons after afferent stimulation can closely parallel selective neuronal injury, suggesting that the presence of HSPs indicates potentially lethal cell stress and expression of HSPs after cerebral ischemia may be related to the intensity of ischemic stress. ${ }^{25}$ In our experimental model, the ischemic insult immediately preceded hypothermic CPB and HCA. The hypothermia in this model is likely delaying the protein synthesis, resulting even less HSP production. Besides, HSP induction requires DNA transcription and translation to 


\section{Control HS PC NPC}

HSP 70
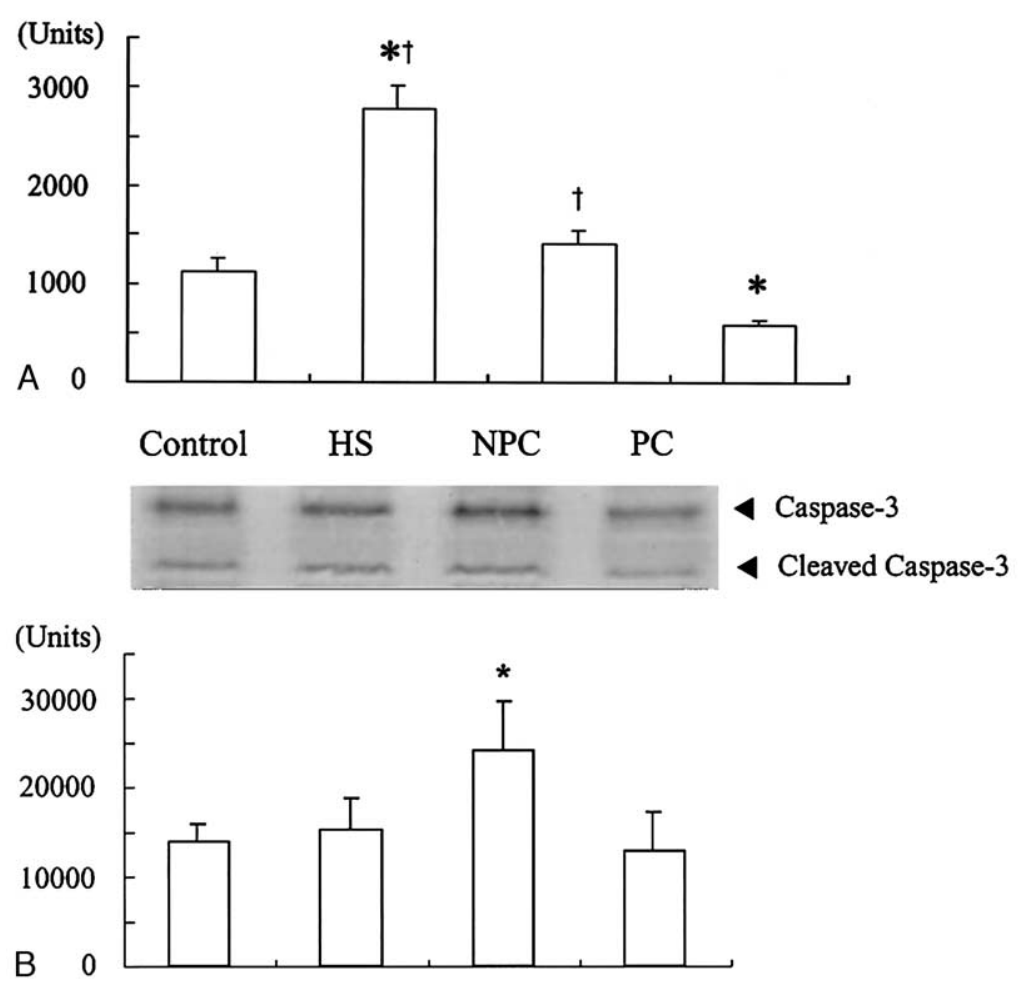

Figure 3. Western blot analyses of HSP70 (A) and caspase-3 (B) levels. In the NPC group, HSP70 levels were significantly lower $\left({ }^{*} P<.05\right.$ vs control group; $+P<.05$ vs NPC group) and activated caspase-3 levels were significantly higher ( ${ }^{*} P<.05$ vs control group) compared with other groups.

occur, a process requiring at least 4 hours. However, this current study shows that HCA can induce hippocampal CA1 cell apoptosis, which could be ameliorated by IP or heat shock manipulations. The significant difference in the pattern of HSP70 expression between IP and HSP groups, in this study using semi-quantitative methods, implies that HSP70 might not be the major factor in the neuroprotection mechanism of early window of IP under HCA.

HSP overexpression protects CA1 region of the hippocampal neurons from global cerebral ischemia, in part by increasing Bcl-2 expression. ${ }^{26}$ The induction of immediate early genes (IEGs) proteins, such as c-Fos, is closely associated with the molecular process determining neuronal survival after global cerebral ischemia, and HSPs have an important role in neuronal survival when present at the onset of the ischemic insult. ${ }^{27}$ In response to cerebral ischemia, neurons in the central nervous system express c-Fos, an IEG. ${ }^{28}$ The functional significance of c-Fos expression after ischemia is controversial. Prolonged c-Fos induction can precede postischemic neuronal death, and c-Fos and its gene products are involved in neuronal injury ${ }^{29}$ and in the induction of apoptotic genes that lead to cell death, though its expression is essential for recovery from ischemia. ${ }^{30} \mathrm{~A}$ close correlation exists between prompt induction of c-Fos and c-JUN with neuronal survival after ischemic stress, and the induction of IEG proteins may be closely related to the molecular process determining neuronal survival after global cerebral ischemia, although the exact mechanism is still uncertain. ${ }^{24} \mathrm{~A}$ close correlation was also found between prompt induction of c-Fos/c-JUN and the absence of permanent ischemic or postischemic damage. ${ }^{24}$ The significance of c-Fos protein expression underlies the fact that it forms transcription factor-AP1 complex by dimerization with Jun family protein and that it regulates late gene expression, such as HSPs, basic fibroblast growth factor, nerve growth factor, and neurotrophins, ${ }^{29}$ which indicate that the potentiation of c-Fos expression may be an underlying neuroprotective mechanism after ischemia. The current data show that c-Fos protein is induced only after CPB with circulatory arrest (not in the control group) and is 

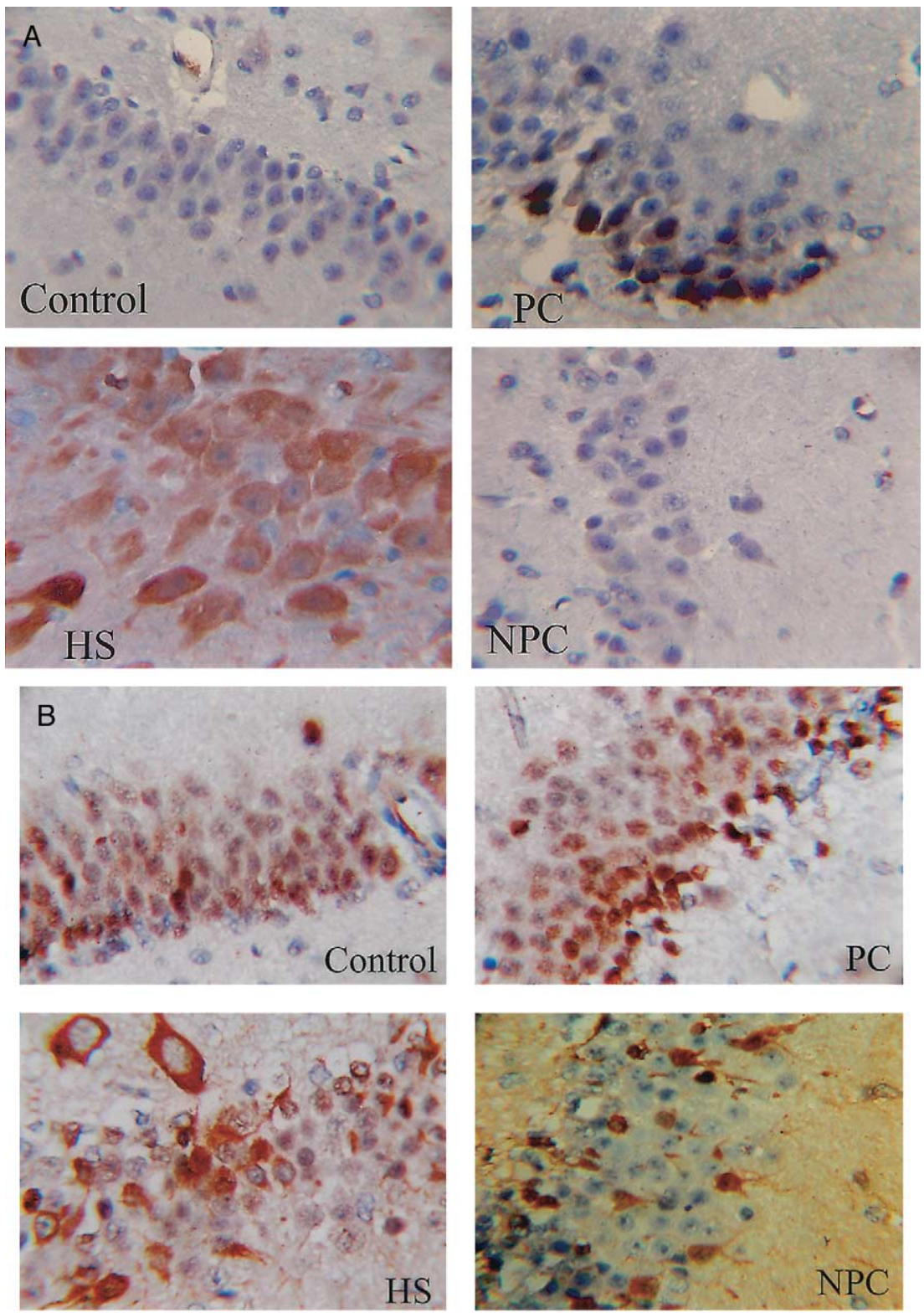

Figure 4. Correlation between induction of c-Fos, BcI-2, HSP70, and caspase-3 in the hippocampus after 2-hour HCA and 4-hour reperfusion. In the vulnerable hippocampal CA1 region, induction of Bcl-2 (A), c-Fos (B), and HSP70 (C) was significant in the PC and HS groups, and significantly apoptotic neuronal damage was visualized as expression of the caspase-3 proteins (D) in the NPC group.

positively correlated with neuronal survival. However, cFos expression was significantly inhibited with elevated caspase-3 expression and occurrence of apoptosis of CA1 neurons in the NPC group. The decreased level of c-Fos may result from a significant, synthesis-inhibiting ischemiareperfusion insult to the CA1 neuron.

The present study demonstrates that (1) CPB can induce IEG protein expression with trivial neuronal damage; (2) IP confers neuroprotection to hippocampal CA1 cells, which is associated with amelioration of apoptosis under HCA; (3) heat shock before global ischemia under HCA can significantly inhibit neuronal damage in hippocampal CA1 cells; and (4) IP activation before HCA is associated with only mild HSP expression within the first window of protection, suggesting that other factors play a major role in early phase of preconditioning-induced neuroprotection. It is hoped that these results contribute to the characterization of physiological markers associated with enhanced neuronal recovery following HCA and will help to develop more relevant therapeutic approaches for cerebral protection. 

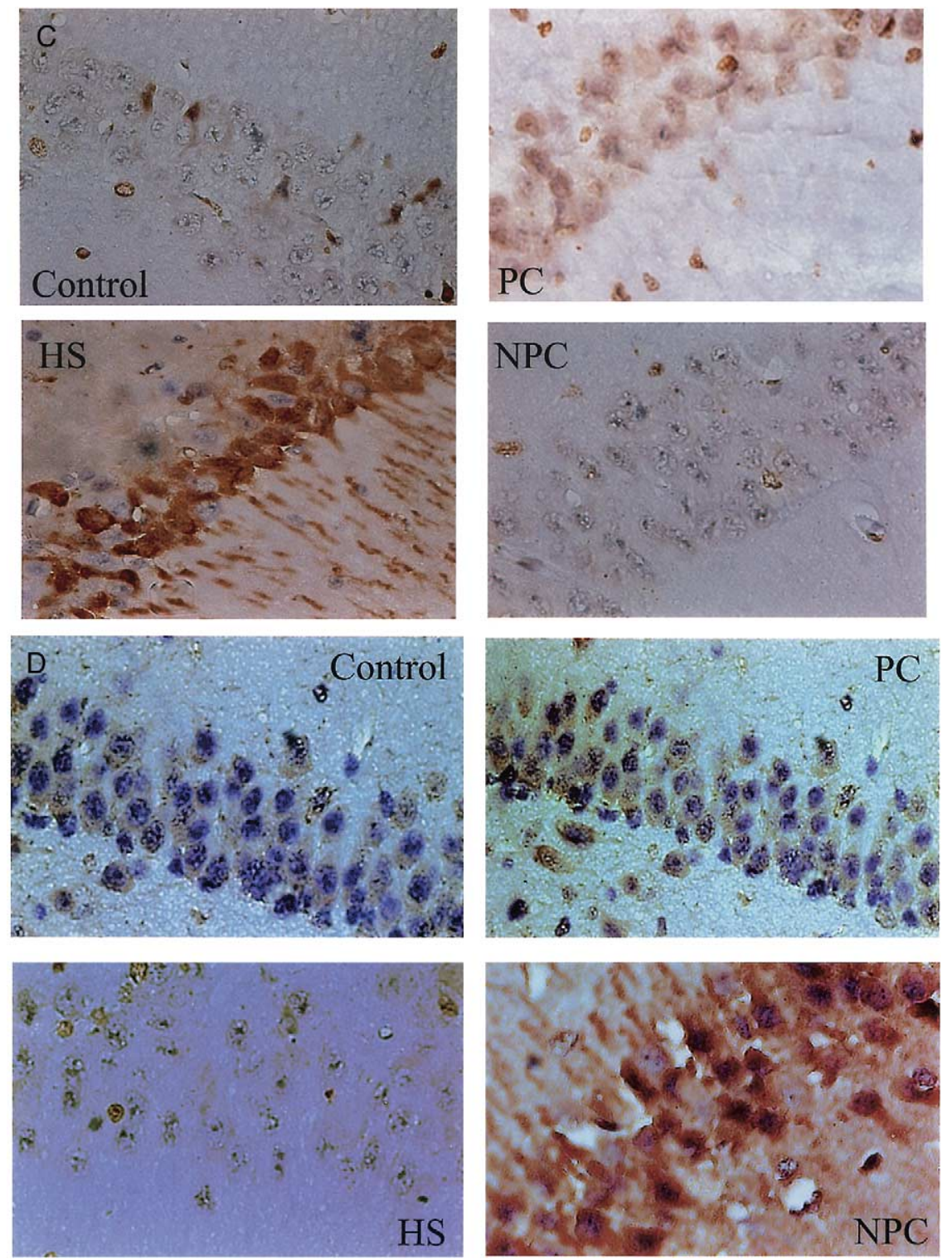

Figure 4. Cont'd. C and D. For legend see Figure 4.

\section{References}

1. Griepp RB, Stinson EB, Hollingsworth JF, Buehler D. Prosthetic replacement of the aortic arch. J Thorac Cardiovasc Surg. 1975;70: 1051-63.

2. Forbess JM, Visconti KJ, Bellinger DC, Howe RJ, Jonas RA. Neurodevelopmental outcomes after biventricular repair of congenital heart defects. J Thorac Cardiovasc Surg. 2002;123:631-9.

3. McCullough JN, Zhang N, Reich D, Juvonen TS, Klein JJ, Spielvogel D, et al. Cerebral metabolic suppression during hypothermic circulatory arrest in humans. Ann Thorac Surg. 1999;67:1895-9.

4. Lin PJ, Chang CH, Tan PP, Chang CN, Lee ST, Wang CC, et al. Prolonged circulatory arrest in moderate hypothermia with retrograde cerebral perfusion. Is brain ischemic? Circulation. 1996;94:II169-72.

5. Redmond JM, Gillinov AM, Zehr KJ, Blue ME, Troncoso JC, Reitz BA, et al. Glutamate excitotoxicity: a mechanism of neurologic injury associated with hypothermic circulatory arrest. J Thorac Cardiovasc Surg. 1994;107:776-87.

6. Tseng EE, Brock MV, Lange MS, Blue ME, Troncoso JC, Kwon CC, et al. Neuronal nitric oxide synthase inhibition reduces neuronal apoptosis after hypothermic circulatory arrest. Ann Thorac Surg. 1997;64: 1639-47.

7. Pulsinelli WA, Brierley JB, Plum F. Temporal profile of neuronal damage in a model of transient forebrain ischemia. Ann Neurol. 1982;11:491-8.

8. Scmidt-Kastner R, Freund TF. Selective vulnerability of the hippocampus in brain ischemia. Neuroscience. 1991;40:599-636.

9. Blondeau N, Plamondon H, Richelme C, Heurteaux C, Lazdunski M. $\mathrm{K}_{\mathrm{ATP}}$ channel openers, adenosine agonists and epileptic preconditioning are stress signals inducing hippocampal neuroprotection. Neuroscience. 2000;100:465-74.

10. Kitagawa K, Matsumoto M, Tagaya M, Hata R, Ueda H, Niinobe M, et al. "Ischemic tolerance" phenomenon found in the brain. Brain Res. 1990;528:21-4.

11. Masushima K, Hakim AM. Transient forebrain ischemia protects against subsequent focal cerebral ischemia without changing cerebral perfusion. Stroke. 1995;26:1047-52. 
12. Perdrizet GA, Lena CJ, Shapiro DS, Rewinski MJ. Preoperative stress conditioning prevents paralysis after experimental aortic surgery: increased heat shock protein content is associated with ischemic tolerance of the spinal cord. J Thorac Cardiovasc Surg. 2002;124:162-70.

13. de Haan P, Vanicky I, Jacobs MJ, Bakker O, Lips J, Meylaerts SA, et al. Effect of ischemic pretreatment on heat shock protein 72, neurologic outcome, and histopathologic outcome in a rabbit model of spinal cord ischemia. J Thorac Cardiovasc Surg. 2000;120:513-9.

14. Yeh CH, Wang YC, Wu YC, Chu JJ, Lin PJ. Continuous tepid blood cardioplegia can preserve coronary endothelium and ameliorate the occurrence of cardiomyocyte apoptosis. Chest. 2003;123:1647-54.

15. Shake JG, Peck EA, Marban E, Gott VL, Johnston MV, Troncoso JC, et al. Pharmacologically induced preconditioning with diazoxide: a novel approach to brain protection. Ann Thorac Surg. 2001;72:184954.

16. Shum-Tim D, Tchervenkov CI, Jamal A-M, Nimeh T, Luo C-Y, Chedrawy E, et al. Systemic steroid pretreatment improves cerebral protection after circulatory arrest. Ann Thorac Surg. 2001;72:1465-72.

17. Harris DN, Bailey SM, Smith PL, Taylor KM, Oatridge A, Bydder GM. Brain swelling in first hour after coronary artery bypass surgery. Lancet. 1993;342:586-7.

18. Hagl C, Tatton NA, Khaladj N, Zhang N, Nandor S, Insolia S, et al. Involvement of apoptosis in neurological injury after hypothermic circulatory arrest: a new target for therapeutic intervention? Ann Thorac Surg. 2001;72:1457-64.

19. Buttner T, Weyers S, Postert T, Sprengelmeyer R, Kuhn W. S-100 protein: serum marker of focal brain damage after ischemic territorial MCA infarction. Stroke. 1997;28:1961-5.

20. Murry CE, Jennings RB, Reimer KA. Preconditioning with ischemia: a delay of lethal cell injury in ischemic myocardium. Circulation. 1986;74:1124-36.
21. Perex-Pinzon MA, Vitro TM, Dietrich WD, Sick TJ. The effect of rapid preconditioning on the microglial, astrocytic and neuronal consequences of global cerebral ischemia. Acta Neuropathol (Berl). 1999; 97:495-501.

22. Gerner EW, Schneider MJ. Induced thermal resistance in HeLa cells. Nature. 1975;256:500-2.

23. Truettner J, Busto R, Zhao W, Ginsberg MD, Perez-Pinzon MA. Effects of ischemic preconditioning on the expression of putative neuroprotective genes in the rat brain. Brain Res Mol Brain Res. 2002;103:106-15.

24. Lee JE, Yenari MA, Sun GH, Xu L, Emond MR, Cheng D, et al. Differential neuroprotection from human heat shock protein 70 overexpression in in vitro and in vivo models of ischemia and ischemia-like conditions. Exp Neurol. 2001;170:129-39.

25. Shaver EG, Welsh FA, Sutton LN, Mora G, Gennarelli LM, Norwood CR. Deep hypothermia diminishes the ischemic induction of heat shock protein-72 mRNA in piglet brain. Stroke. 1995;26:1273-7.

26. Kelly S, Zhang ZJ, Zhao H, Xu L, Giffard RG, Sapolsky RM, et al. Gene transfer of HSP72 protects cornu ammonis 1 region of the hippocampus neurons from global ischemia: influence of Bcl-2. Ann Neurol. 2002;52:160-7.

27. Takemoto O, Tomimoto H, Yanagihara T. Induction of c-Fos and c-jun gene products and heat shock protein after brief and prolonged cerebral ischemia in gerbils. Stroke. 1995;26:1639-48.

28. Kogure K, Kato H. Altered gene expression in cerebral ischemia. Stroke. 1993;24:2121-7.

29. Cho S, Park EM, Kim Y, Liu N, Gal J, Volpe BT, et al. Early c-Fos induction after cerebral ischemia: a possible neuroprotective role. J Cereb Blood Flow Metab. 2001;21:550-6.

30. Akins PT, Liu PK, Hsu CY. Immediate early gene expression in response to cerebral ischemia: friend or foe? Stroke. 1996;27:1682-7. 